\title{
Construction of an Arabic computerized battery for cognitive rehabilitation of children with specific learning disabilities
}

This article was published in the following Dove Press journal: Neuropsychiatric Disease and Treatment

\author{
Wafaa MA Farghaly' \\ Mohamed A Ahmed' \\ Hamdy N El-Tallawy' \\ Taha AH Elmestikawy ${ }^{2}$ \\ Reda Badry' \\ Mohammed Sh Farghaly ${ }^{3}$ \\ Montaser S Omar ${ }^{3}$ \\ Amr Sayed Ramadan \\ Hussein ${ }^{4}$ \\ Mohammed Salamah ${ }^{5}$ \\ Adel T Mohammed' \\ 'Department of Neurology, Faculty \\ of Medicine, Assiut University, Assiut, \\ Egypt; '2Department of Psychology, \\ Faculty of Arts, Assiut University, \\ Assiut, Egypt; ${ }^{3}$ Department of \\ Educational Psychology, Faculty of \\ Education, Assiut University, Assiut, \\ Egypt; ${ }^{4}$ Department of Hearing \\ Disability, Faculty of Sciences of \\ Special Needs, Beni-Suef University, \\ Beni-Suef, Egypt; ${ }^{5}$ Department of \\ Phoniatrics, Faculty of Medicine, \\ Assiut University, Assiut, Egypt
}

Correspondence: Amr Sayed Ramadan Hussein

Department of Hearing Disability, Faculty of Sciences of Special Needs, Beni-Suef University, 5th Western Road, Beni-Suef 625I I, Egypt

Tel +20 II 40507779

Fax +20 882351838

Email amr.sayed_ssn@bsu.edu.eg
Purpose: The aim of this study was to design an Arabic computerized battery of cognitive skills for training children with specific learning disabilities (SLD).

Subjects and methods: Nineteen students from fourth grade primary schools in Assiut, Egypt, who were previously diagnosed with SLD, agreed to participate in the rehabilitation program. The study passed through four stages: first stage, detailed analysis of the cognitive profile of students with SLD ( $\mathrm{n}=19)$, using a previously constructed diagnostic cognitive skill battery, to identify deficits in their cognitive skills; second stage, construction of an Arabic computerized battery for cognitive training of students with SLD; third stage, implementation of the constructed training program for the students, each tailored according to his/her previously diagnosed cognitive skill deficit/deficits; and fourth stage, post-training re-evaluation of academic achievement and cognitive skills' performance.

Results: Students with SLD have a wide range of cognitive skill deficits, which are more frequent in auditory cognitive skills (68.4\%) than in visual cognitive skills (64.1\%), particularly in phonological awareness and auditory sequential memory (78.9\%). Following implementation of the training program, there was a statistically significant increase $(P<0.001)$ in the mean scores of total auditory and visual cognitive skills, as well as in academic achievement $(P<0.001)$ of the study group.

Conclusion: Remediation-oriented diagnosis of cognitive skills, when tailored according to previously diagnosed cognitive deficits, leads to the improvement in learning abilities and academic achievement of students with SLD.

Keywords: cognitive skills, learning disabilities, cognitive rehabilitation, computerized training, dyslexia, dyscalculia, dysgraphia

\section{Introduction}

A child who has a learning disability that is not attributed to visual, hearing, and motor disabilities, mental retardation, emotional disturbance, or environmental, cultural, or economic disadvantages is termed to have specific learning disabilities (SLD). ${ }^{1}$

Current computer technology has positive impacts on education. It may be a part of the long-term solution for difficulties of dyslexics and others at risk from learning disabilities. ${ }^{2}$ It supports and enhances children's creativity and self-esteem and helps children to develop a fearless, joyful attitude toward all learning situations. The use of a game in the training program contributes in grasping the child's attention and preventing boredom. This is especially significant for those students with disabilities. ${ }^{3,4}$

Several studies aimed at remediating individualized aspects of learning disabilities, such as visuo-graphemic deficiencies, through the facilitation of low-level visual processing ${ }^{5,6}$ or through video games, ${ }^{7,8}$ phonological awareness,,${ }^{9,10}$ auditory processes, ${ }^{11,12}$ and allophonic 
perception, ${ }^{11,13,14}$ but the current study aimed at rehabilitating all cognitive aspects of learning disabilities through a computerized battery that includes games to develop these aspects. ${ }^{15}$

\section{Subjects and methods Subjects}

A total of 106 of the 660 students of fourth grade governmental schools in Assiut were diagnosed with SLD. The age of the sample ranged from $<10$ to 11 years, with 352 males and 308 females.

They fulfilled the following diagnostic criteria:

1. Poor scholastic achievement as evidenced by obtaining less than (mean - SD) one or more of the following standardized achievement tests:

a Arabic reading test (ART); ${ }^{16}$

b Writing test (specifically designed for this study, with the spelling part of ART);

c Mathematics test. ${ }^{17}$

2. IQ $\geq 90$ on the third Arabic version ${ }^{18}$ of the Wechsler Intelligence Scale for Children (WISC-R) test. ${ }^{19}$

3. No apparent motor, sensory, or psychiatric problems as evidenced by:

a Complete history, general, and neurological examinations;

b No apparent special sensory deprivation (hearing or visual) as evidenced by basic audiological and ophthalmological examinations;

c No attention-deficit hyperactive disorder (ADHD) as assessed by the Arabic version ${ }^{20}$ of Conners test ${ }^{21}$ and Diagnostic and Statistical Manual of Mental Disorders, 5th Edition (DSM-V) diagnostic criteria.

Of the 106 students diagnosed with SLD, only 19 students agreed to participate in the cognitive rehabilitation program. This study was approved by the Ethics Committee of Assiut University, Egypt.

Parents of the students gave their written informed consent for the participation of their children in the study for the diagnosis and rehabilitation of SLD. They gave their agreement and accompanied their children during the rehabilitation sessions. They were informed that they could withdraw their children at any time during the study.

\section{Methodology}

The study passed through the following stages.

\section{Stage I}

This stage involved detailed analysis of the cognitive profile of students with SLD ( $n=19)$ using the previously constructed diagnostic cognitive skill battery ${ }^{22}$ to identify deficits in their cognitive skills, which necessitate rehabilitation.

\section{Stage 2}

This stage involved construction of an extended Arabic computerized battery for the cognitive training of students with SLD.

The constructed battery was designed to include rehabilitation for the following cognitive skills:

1. Visual cognitive skills training on:
a Visual closure;
b Visual discrimination;
c Visual memory and visual sequential memory;
d Visual comprehension;
e Visuo-spatial ability;
f Whole-part relationship;
g Visual-motor integration test.

2. Auditory cognitive skills training on:
a Phonological awareness;
b Auditory discrimination;
c Auditory memory and sequencing memory;
d Auditory comprehension;
e Auditory-sustained vigilance (attention).

3. Writing training program.

Writing training for disabled students was carried out with the help of a special training computerized program that presents the method of writing of each of the alphabetic letters (at the beginning, middle, and end of the word) as well as how to write digits (1-10) using explicit, systematic motivating instructions. It includes combined phonological with orthographic presentation of all the 28 alphabetic Arabic letters, so that children can understand the phonological structure and orthographic presentation (written symbol) of the Arabic letters (ie, phoneme-grapheme representation). Then, further script activities (including words and sentences) were conducted by the student at home for repeated training under the supervision of his/her parents, and revised by the skilled trainer.

The activities in the designed training program were arranged in a hierarchy from simple tasks to more complex ones and presented in an interesting form using a game to grasp the child's attention and prevent boredom. The training program was performed under the supervision of experts and one of the parents of the trainee. During implementation of the training program, the students were relaxed and encouraged by the supervisor. Moreover, small gifts were given to each student to encourage them to complete the training sessions.

\section{Stage 3}

This stage involved implementation of the training program for the students with SLD ( $n=19$ who accepted to participate in the rehabilitation program), each tailored according to his/her previously diagnosed cognitive skill deficits. 


\section{Training procedure}

1. Each student received training sessions for both auditory and visual cognitive skills as well as the writing training program.

2. Each student attended three sessions per week (every other day), for a total of 54 sessions in 18 weeks ( 2 weeks for writing training skills, 8 weeks for visual skills, and 8 weeks for auditory skills). Thus, each student attended 54 training sessions (six sessions for writing program, 24 sessions for visual skills, and 24 sessions for auditory cognitive skills).

3. Every session lasted from 90 to 120 minutes.

4. Students were asked to attend, together with one or both of their parents.

5. The training program was implemented in the Neuroepidemiology Research Center of the Faculty of Medicine, Assiut University.

6. Training was conducted during the end-year holiday in the morning.

7. Students were divided into two groups: the first group consisted of 10 students and the second group consisted of nine students. On each day, two shifts were held; the first shift was from 9 am to 11 am and the second shift was from 12 am to $2 \mathrm{pm}$.

8. Each student was asked to attend at the shift time suitable for him/her and to his/her parents.

9. The program was implemented under the supervision of three neurologists and two staff members from the Faculty of Education.

10. A follow-up sheet was constructed for each student to evaluate the time and errors for each item of the training program.

11. The child was allowed to pass to the next level of the program when he/she mastered the current one, with no time limits.

\section{Stage 4}

This stage involved re-evaluation of academic achievement and cognitive skills' performance at the end of the implementation of the constructed cognitive training program.

At the end of the training sessions, re-assessment of the achievement of those students using the ART, mathematics test, and writing test as well as the constructed diagnostic computerized visual and auditory cognitive skills' battery ${ }^{22}$ was carried out to evaluate the impact of the neuro-cognitive training program on cognitive skill performance and academic achievement of students with SLD.

\section{Statistical analysis}

Statistical analysis was performed using SPSS Version 20 (SPSS Inc., Chicago, IL, USA). Number and percentage, mean and standard deviation, were used for descriptive statistical analysis. For differences between pre- and post-training mean scores, independent $t$-test was used, and statistical significance was set at $P<0.05$.

\section{Results}

Tables 1-3 show that the most frequently encountered deficits in cognitive skills among the students with SLD were phonological awareness and auditory sequential memory (78.9\% for each) followed by total auditory memory, total auditory attention, and total auditory cognitive skills (68.4\% for each).

Table 1 shows that there is a statistically significant increase in the mean scores of total visual cognitive skills, and in all its seven main sub-items for students with SLD after the implementation of the training program, except for visual comprehension. However, in some individual subtests, the increase in the post-training mean score did not reach a statistically significant level.

Table 2 shows that there is a statistically significant increase in the mean scores of the total auditory cognitive skills, and in all its sub-items of the study group, after implementation of the training program, except for rhyming and phoneme blending where the increase did not reach a statistically significant level.

Table I Visual cognitive profile of students with SLD and the identified points of weakness in their visual cognitive skills ( $n=19$ )

\begin{tabular}{|c|c|c|c|c|c|c|c|c|c|c|c|c|c|c|c|c|c|c|c|}
\hline \multirow[t]{2}{*}{ Visual cognitive skills } & \multicolumn{19}{|c|}{ Students } \\
\hline & I & 2 & 3 & 4 & 5 & 6 & 7 & 8 & 9 & 10 & I I & 12 & 13 & 14 & 15 & 16 & 17 & 18 & 19 \\
\hline Visual closure & & & & & & & $\sqrt{ }$ & & & & & & & & & & $\sqrt{ }$ & $\sqrt{ }$ & \\
\hline Visuo-spatial & $\sqrt{ }$ & & & & & & & & & & & & & & & & $\sqrt{ }$ & $\sqrt{ }$ & \\
\hline Visual memory & $\sqrt{ }$ & & & & & $\sqrt{ }$ & $\sqrt{ }$ & & $\sqrt{ }$ & & $\sqrt{ }$ & & & & $\sqrt{ }$ & & & $\sqrt{ }$ & \\
\hline Whole-part relationship & & & & & & $\sqrt{ }$ & & & $\sqrt{ }$ & & & & & & & & & $\sqrt{ }$ & \\
\hline \multicolumn{20}{|l|}{ Visual discrimination } \\
\hline Visual comprehension & & & $\sqrt{ }$ & & & & & & & & $\sqrt{ }$ & & & & $\sqrt{ }$ & & & $\sqrt{ }$ & \\
\hline Total visual & $\sqrt{ }$ & & & & $\sqrt{ }$ & $\sqrt{ }$ & $\sqrt{ }$ & $\sqrt{ }$ & $\sqrt{ }$ & & $\sqrt{ }$ & & $\sqrt{ }$ & & $\sqrt{ }$ & & $\sqrt{ }$ & $\sqrt{ }$ & $\sqrt{ }$ \\
\hline Visuo-motor & & & & & & & & & & & & $\sqrt{ }$ & & & & & & & $\sqrt{ }$ \\
\hline
\end{tabular}

Abbreviation: SLD, specific learning disabilities. 
Table 2 Auditory cognitive profile of students with SLD and the identified points of weakness in their auditory cognitive skills $(n=19)$

\begin{tabular}{|c|c|c|c|c|c|c|c|c|c|c|c|c|c|c|c|c|c|c|c|}
\hline \multirow[t]{2}{*}{ Visual cognitive skills } & \multicolumn{19}{|c|}{ Students } \\
\hline & $\mathbf{I}$ & 2 & 3 & 4 & 5 & 6 & 7 & 8 & 9 & 10 & II & 12 & 13 & 14 & 15 & 16 & 17 & 18 & 19 \\
\hline Phonological awareness & $\sqrt{ }$ & & $\sqrt{ }$ & $\sqrt{ }$ & $\sqrt{ }$ & $\sqrt{ }$ & $\sqrt{ }$ & $\sqrt{ }$ & $\sqrt{ }$ & & $\sqrt{ }$ & $\sqrt{ }$ & & $\sqrt{ }$ & & $\sqrt{ }$ & $\sqrt{ }$ & $\sqrt{ }$ & $\sqrt{ }$ \\
\hline Auditory discrimination & $\sqrt{ }$ & & & & & $\sqrt{ }$ & $\sqrt{ }$ & $\sqrt{ }$ & $\sqrt{ }$ & & $\sqrt{ }$ & $\sqrt{ }$ & & $\sqrt{ }$ & $\sqrt{ }$ & & $\sqrt{ }$ & $\sqrt{ }$ & $\sqrt{ }$ \\
\hline Auditory memory & $\sqrt{ }$ & $\sqrt{ }$ & $\sqrt{ }$ & $\sqrt{ }$ & $\sqrt{ }$ & & & & & $\sqrt{ }$ & $\sqrt{ }$ & $\sqrt{ }$ & & $\sqrt{ }$ & & $\sqrt{ }$ & $\sqrt{ }$ & $\sqrt{ }$ & $\sqrt{ }$ \\
\hline Auditory sequential memory & $\sqrt{ }$ & $\sqrt{ }$ & & & $\sqrt{ }$ & $\sqrt{ }$ & $\sqrt{ }$ & $\sqrt{ }$ & $\sqrt{ }$ & $\sqrt{ }$ & & $\sqrt{ }$ & $\sqrt{ }$ & $\sqrt{ }$ & $\sqrt{ }$ & & $\sqrt{ }$ & $\sqrt{ }$ & $\sqrt{ }$ \\
\hline Auditory comprehension & $\sqrt{ }$ & $\sqrt{ }$ & & & & $\sqrt{ }$ & & $\sqrt{ }$ & $\sqrt{ }$ & $\sqrt{ }$ & $\sqrt{ }$ & & & $\sqrt{ }$ & $\sqrt{ }$ & & $\sqrt{ }$ & $\sqrt{ }$ & $\sqrt{ }$ \\
\hline Auditory attention & $\sqrt{ }$ & & $\sqrt{ }$ & $\sqrt{ }$ & $\sqrt{ }$ & & & $\sqrt{ }$ & $\sqrt{ }$ & & $\sqrt{ }$ & $\sqrt{ }$ & & & $\sqrt{ }$ & $\sqrt{ }$ & $\sqrt{ }$ & $\sqrt{ }$ & $\sqrt{ }$ \\
\hline Total auditory & $\sqrt{ }$ & $\sqrt{ }$ & & & $\sqrt{ }$ & $\sqrt{ }$ & & $\sqrt{ }$ & $\sqrt{ }$ & & $\sqrt{ }$ & $\sqrt{ }$ & & $\sqrt{ }$ & $\sqrt{ }$ & & $\sqrt{ }$ & $\sqrt{ }$ & $\sqrt{ }$ \\
\hline
\end{tabular}

Abbreviation: SLD, specific learning disabilities.

Table 3 shows that there is a statistically significant increase in the mean scores of the ART, mathematics test, and writing test of the studied group after implementation of the training program.

\section{Discussion}

The increased awareness of the impact of SLD on children and consequently on their parents and the limited resources regarding the therapy of Arabic-speaking children with SLD sheds light on the importance of the development of a structured training program for these children. The training program presented in this study is an electronic one, and is computerized and constructed in an Arabic language for the enhancement of both visual and auditory cognitive skills that are mostly involved in the process of learning. The implementation of this newly constructed electronic program occurred according to the domains of deficits in both visual and auditory cognitive profiles as diagnosed by the previously constructed diagnostic battery. ${ }^{22}$

Dyslexia, a type of specific learning disability, is characterized by difficulties with accurate and/or fluent word recognition and by poor spelling and decoding abilities. According to the International Dyslexia Association, ${ }^{23}$ it typically results from a deficit in the phonological component of language. ${ }^{24-27}$ Previously accumulated findings have demonstrated that cognitive training of children using multisensory modalities, such as visual, auditory, and visuo-motor modalities, has a beneficial impact on their learning skills and achievement. ${ }^{28,29}$

In the present study, there was a significant difference between pretraining and post-training mean scores of students with SLD regarding phonological awareness (Tables 4 and 5). This improvement in phonological

Table 3 Percentage of students with SLD having visual and auditory cognitive skill deficits (less than cutoff value for each test) before and after training

\begin{tabular}{|c|c|c|c|c|c|c|c|c|}
\hline \multirow[t]{3}{*}{ Items } & \multicolumn{4}{|c|}{$\begin{array}{l}\text { Percentage of students having pretraining } \\
\text { scores, } n=19\end{array}$} & \multicolumn{4}{|c|}{$\begin{array}{l}\text { Percentage of students having post- } \\
\text { training scores, } n=19\end{array}$} \\
\hline & \multicolumn{2}{|c|}{ Less than cutoff } & \multicolumn{2}{|c|}{ More than cutoff } & \multicolumn{2}{|c|}{ Less than cutoff } & \multicolumn{2}{|c|}{ More than cutoff } \\
\hline & $\mathbf{n}$ & $\%$ & $\mathbf{n}$ & $\%$ & $\mathbf{n}$ & $\%$ & $\mathbf{n}$ & $\%$ \\
\hline Total phonological awareness & 15 & 78.9 & 4 & 21.1 & 1 & 5.27 & 18 & 94.73 \\
\hline Total auditory discrimination & 12 & 63.1 & 7 & 36.9 & 2 & 10.54 & 17 & 89.46 \\
\hline Auditory sequential memory & 15 & 78.9 & 4 & 21.1 & 0 & 0 & 19 & 100 \\
\hline Total auditory memory & 13 & 68.4 & 6 & 31.6 & 3 & $|5.8|$ & 16 & 84.19 \\
\hline Total auditory comprehension & 12 & 63.1 & 7 & 36.9 & 3 & $|5.8|$ & 16 & 84.19 \\
\hline Total auditory attention & 13 & 68.4 & 6 & 31.6 & 3 & $|5.8|$ & 16 & 84.19 \\
\hline Total auditory & 13 & 68.4 & 6 & 31.6 & 1 & 5.27 & 18 & 94.73 \\
\hline Total visual closure & 3 & 15.7 & 16 & 84.3 & 0 & 0 & 19 & 100 \\
\hline Total spatial relations & 3 & 15.7 & 16 & 84.3 & 1 & 5.27 & 18 & 94.73 \\
\hline Total visual memory & 7 & 36.8 & 12 & 63.2 & I & 5.27 & 18 & 94.73 \\
\hline Total whole-part relationship & 3 & 15.7 & 16 & 84.3 & I & 5.27 & 18 & 94.73 \\
\hline Total visual discrimination & 0 & 0 & 19 & 100 & - & - & - & - \\
\hline Visual comprehension & 4 & 21.05 & 15 & 78.95 & I & 5.27 & 18 & 94.73 \\
\hline Total visual & 12 & 63.1 & 7 & 36.9 & I & 5.27 & 18 & 94.73 \\
\hline Visuo-motor & 2 & 10.5 & 17 & 89.5 & 0 & 0 & 19 & 100 \\
\hline
\end{tabular}

Abbreviation: SLD, specific learning disabilities. 
awareness together with other improved auditory and visual cognitive abilities was reflected in improved academic achievement (reading, writing and mathematics). This goes hand in hand with the work of $\mathrm{Lie}^{30}$ who proved that training in phonological awareness helps developing reading and spelling skills. Furthermore, Hecht et al ${ }^{31}$ found that the relationships between phonemic awareness and spelling skills are bidirectional. The amount of exposure that children had to the treatment intervention contributed uniquely to individual differences in post-test levels of phonemic awareness and spelling.

Moreover, Shaywitz ${ }^{32}$ found that interventions targeting phonological awareness, particularly in the early grades, led to improvement in word reading skills. However, remediation studies of students with developmental dyslexia indicated that audio-visual training with emphasis on training of phonological awareness has been shown to be effective to improve letter-sound conversion skills and has long-lasting effects especially in the improvement of their reading comprehension. ${ }^{28,33,34}$ Considerable progress has been made through early intervention with explicit phonological awareness and decoding instructions to prevent SLD in many students; ${ }^{35,36}$ despite this, there are still students with persisting SLD in the upper elementary and middle school grades. ${ }^{37,38}$

Written language, a relatively recent human intervention, developed in response to spoken language aiming at graphic representation of spoken language. ${ }^{39,40}$ The graphemes in alphabetic writing systems transcribe the phonetic elements of language (written symbols). ${ }^{41}$ Accordingly, the phonological processing system is supposed to be essential for reading and spelling ${ }^{40,42}$ and children with dyslexia having deficits in the phonological processing system face difficulties acquiring grapheme-phoneme correspondence rules and hence defective reading and spelling.

In the current study, implementation of the audio-visual computerized program, which presents explicit and systematic instructions for transcription of the phonemic element of each one of the alphabetic Arabic letters (at the beginning, middle, and end of the word) to their corresponding grapheme, was associated with significant improvement in children's visuo-motor skills (58.8 versus 74.4 ; Table 4) and writing achievement tests (66.2 versus 99.9; Table 6). This was consistent with the work of Oliver ${ }^{43}$ who found that there was improvement in the performance of writing

Table 4 Comparison between the mean scores of basic (pretraining) and post-training visual cognitive skill profiles of students with SLD ( $\mathrm{n}=19$ cases)

\begin{tabular}{|c|c|c|c|c|}
\hline \multirow[t]{2}{*}{ Visual cognitive skills } & \multirow{2}{*}{$\frac{\text { Basic }}{\text { Mean } \pm \text { SD }}$} & \multirow{2}{*}{$\frac{\text { Post-training }}{\text { Mean } \pm \text { SD }}$} & \multirow[t]{2}{*}{$P$-value } & \multirow{2}{*}{$\begin{array}{l}95 \% \text { confidence } \\
\text { interval }\end{array}$} \\
\hline & & & & \\
\hline The same picture & $4.3 \pm 1.1$ & $4.9 \pm 0.2$ & 0.015 & $-1.13,-0.13$ \\
\hline The same number & $4.8 \pm 0.4$ & $5 \pm 0$ & 0.074 & $-0.33,0.02$ \\
\hline The same word & $4.6 \pm 0.6$ & $4.9 \pm 0.3$ & 0.098 & $-0.58,0.05$ \\
\hline The same letter & $4.9 \pm 0.2$ & $5 \pm 0$ & 0.324 & $-0.16,0.05$ \\
\hline Picture to word & $4.8 \pm 0.6$ & $5 \pm 0$ & 0.154 & $-0.5,0.08$ \\
\hline Total visual closure & $23.5 \pm 2.1$ & $24.8 \pm 0.4$ & 0.011 & $-2.32,-0.32$ \\
\hline The same design & $10.4 \pm 1.5$ & $11.2 \pm 1.3$ & 0.115 & $-1.66,0.19$ \\
\hline Letters' position & $1.8 \pm 0.5$ & $1.9 \pm 0.2$ & 0.411 & $-0.36,0.15$ \\
\hline Words' position & $1.9 \pm 0.2$ & $2 \pm 0$ & 0.324 & $-0.16,0.05$ \\
\hline Numbers' position & $2.6 \pm 0.7$ & $2.9 \pm 0.2$ & 0.064 & $-0.65,0.02$ \\
\hline$x$ new position & $2.7 \pm 0.7$ & $2.8 \pm 0.4$ & 0.376 & $-0.52,0.2$ \\
\hline Different directions & $4.3 \pm 0.9$ & $4.7 \pm 0.7$ & 0.091 & $-1.03,0.08$ \\
\hline Total spatial relations & $23.8 \pm 2.9$ & $25.6 \pm 2.4$ & 0.038 & $-3.57,-0.11$ \\
\hline Sequential memory for letters & $6.2 \pm 1.2$ & $6.8 \pm 1.2$ & 0.106 & $-1.4,0.14$ \\
\hline Sequential memory for words & $6.1 \pm 2.3$ & $7.3 \pm 1.2$ & 0.058 & $-2.36,0.04$ \\
\hline Sequential memory for numbers & $4.7 \pm 2$ & $5.8 \pm 1.7$ & 0.077 & $-2.34,0.13$ \\
\hline Picture remembering & $6.8 \pm 0.5$ & $6.9 \pm 0.2$ & 0.245 & $-0.43,0.11$ \\
\hline Shape remembering & $6.1 \pm 1.1$ & $6.8 \pm 0.4$ & 0.011 & $-1.3,-0.18$ \\
\hline Letter remembering & $9 \pm 0.8$ & $9.3 \pm 0.6$ & 0.255 & $-0.72,0.2$ \\
\hline Word remembering & $5.8 \pm 1.1$ & $6.3 \pm 0.7$ & 0.122 & $-1.08,0.13$ \\
\hline Number remembering & $13.1 \pm 1.7$ & $14.3 \pm 1.2$ & 0.022 & $-2.14,-0.18$ \\
\hline Sequential memory for objects & $8.2 \pm 2$ & $9.5 \pm 0.7$ & 0.013 & $-2.24,-0.28$ \\
\hline
\end{tabular}


Table 4 (Continued)

\begin{tabular}{|c|c|c|c|c|}
\hline \multirow[t]{2}{*}{ Visual cognitive skills } & \multirow{2}{*}{$\frac{\text { Basic }}{\text { Mean } \pm \text { SD }}$} & Post-training & $P$-value & \multirow{2}{*}{$\begin{array}{l}95 \% \text { confidence } \\
\text { interval }\end{array}$} \\
\hline & & Mean \pm SD & & \\
\hline Total visual memory & $66 \pm 8.2$ & $72.9 \pm 5.3$ & 0.004 & $-11.49,-2.4$ \\
\hline Maximum and minimum numbers & $4.3 \pm 1.7$ & $5.3 \pm 1.1$ & 0.028 & $-1.98,-0.12$ \\
\hline Object parts & $5.4 \pm 0.9$ & $5.8 \pm 0.5$ & 0.134 & $-0.86,0.12$ \\
\hline Word formation from letters & $6.5 \pm 1.6$ & $7 \pm 1.3$ & 0.268 & $-1.47,0.42$ \\
\hline Total whole-part relationships & $16.2 \pm 3$ & $18.1 \pm 2.5$ & 0.034 & $-3.74,-0.15$ \\
\hline Letters' count & $31.9 \pm 0.2$ & $32 \pm 0$ & 0.324 & $-0.16,0.05$ \\
\hline Numbers' count & $20.5 \pm 0.8$ & $2 I \pm 0$ & 0.005 & $-0.89,-0.17$ \\
\hline Shapes' count & $\mid 8.1 \pm 1$ & $18.4 \pm 0.6$ & 0.169 & $-0.9,0.16$ \\
\hline Animal scanning & $14.5 \pm 1$ & $14.8 \pm 0.4$ & 0.148 & $-0.87,0.14$ \\
\hline Choosing correct letters & $4.8 \pm 0.7$ & $5 \pm 0$ & 0.206 & $-0.54,0.12$ \\
\hline
\end{tabular}

Note: Bold values are the total score of the test (as a whole).

Abbreviation: SLD, specific learning disabilities.

skills of children following the visuo-motor therapy program. an intervention therapy program is of the utmost importance Furthermore, Gerogia ${ }^{44}$ proposed that writing skills are devel- in dealing with the visuo-motor integration (VMI) deficit of oped through practice and feedback mechanisms. Therefore, learning for disabled children.

Table 5 Comparison between the mean scores of basic (pretraining) and post-training auditory cognitive skill profiles of students with SLD ( $n=19$ cases)

\begin{tabular}{|c|c|c|c|c|}
\hline Auditory cognitive skills & $\frac{\text { Basic }}{\text { Mean } \pm \text { SD }}$ & $\frac{\text { Post-training }}{\text { Mean } \pm \text { SD }}$ & $P$-value & $\begin{array}{l}95 \% \text { confidence } \\
\text { interval }\end{array}$ \\
\hline Rhyming & $8.4 \pm 1.6$ & $8.9 \pm 1.2$ & 0.219 & $-1.52,0.36$ \\
\hline Phoneme blending & $8.9 \pm 1.6$ & $9.2 \pm 1.5$ & 0.604 & $-1.28,0.76$ \\
\hline Word segmentation & $3.6 \pm 1.9$ & $5.8 \pm 0.5$ & 0.001 & $-3.12,-1.3$ \\
\hline Recognizing first sound & $2.2 \pm 1.5$ & $4.5 \pm 1.4$ & 0.001 & $-3.28,-1.35$ \\
\hline Total phonological awareness & $23.1 \pm 3.4$ & $28.4 \pm 3.3$ & 0.001 & $-7.57,-3.17$ \\
\hline Sound recognition & $3.6 \pm 1.5$ & $4.5 \pm 0.8$ & 0.020 & $-1.73,-0.16$ \\
\hline Word recognition & $6.2 \pm 2.9$ & $8.4 \pm 1.5$ & 0.005 & $-3.7,-0.72$ \\
\hline Same or different words & $7.5 \pm 2.2$ & $9.5 \pm 1$ & 0.001 & $-3.13,-0.87$ \\
\hline Al Maad & $2.1 \pm 1.3$ & $3.3 \pm 1.1$ & 0.007 & $-1.97,-0.34$ \\
\hline Al Shadd & $2.3 \pm 1.3$ & $3.1 \pm I .1$ & 0.040 & $-1.64,-0.04$ \\
\hline Same starting letter & $2.1 \pm 1.2$ & $3.3 \pm 1.2$ & 0.005 & $-1.94,-0.37$ \\
\hline Total auditory discrimination & $23.7 \pm 6.1$ & $32.1 \pm 3.6$ & 0.001 & $-11.61,-5.02$ \\
\hline Sound remembering & $3.9 \pm 2.7$ & $6.7 \pm 1.8$ & 0.001 & $-4.28,-1.3$ \\
\hline Number remembering & $19.2 \pm 5.8$ & $22.3 \pm 2.4$ & 0.036 & $-6,-0.21$ \\
\hline Word remembering & $11.6 \pm 4.8$ & $14.7 \pm 2.1$ & 0.014 & $-5.54,-0.67$ \\
\hline Phrase remembering & $2.4 \pm 0.8$ & $2.9 \pm 0.3$ & 0.027 & $-0.89,-0.06$ \\
\hline Total auditory memory & $37.2 \pm \mid 2.1$ & $46.6 \pm 4.7$ & 0.003 & $-|5.5|,-3.44$ \\
\hline Auditory sequential memory & $16.9 \pm 8.9$ & $33.6 \pm 3.7$ & 0.001 & $-21.18,-12.19$ \\
\hline Abstract relations & $3.5 \pm 2.6$ & $5.4 \pm 1.9$ & 0.014 & $-3.38,-0.4 \mathrm{I}$ \\
\hline Complete & $6.9 \pm 3$ & $8.8 \pm 1.1$ & 0.013 & $-3.36,-0.43$ \\
\hline Words' rearrangement & $3.2 \pm 1.7$ & $4.5 \pm 0.6$ & 0.003 & $-2.16,-0.47$ \\
\hline Correct or false & $4.9 \pm 1.4$ & $5.7 \pm 0.7$ & 0.055 & $-1.49,0.02$ \\
\hline Listen and answer & $3.1 \pm 1.2$ & $3.8 \pm 1$ & 0.029 & $-1.5,-0.08$ \\
\hline Total auditory comprehension & $21.6 \pm 6.6$ & $28.3 \pm 3.8$ & 0.001 & $-10.19,-3.07$ \\
\hline Nonverbal sound determination & $2.1 \pm 1.7$ & $3.1 \pm 0.9$ & 0.023 & $-1.95,-0.16$ \\
\hline Number determination & $2.7 \pm 2.3$ & $4.4 \pm 1.1$ & 0.005 & $-2.92,-0.55$ \\
\hline Words and phonemes' determination & $8.6 \pm 5.9$ & $13.7 \pm 3$ & 0.002 & $-8.18,-2.03$ \\
\hline Total auditory attention & $13.4 \pm 8.7$ & $21.3 \pm 4.2$ & 0.001 & $-|2.38,-3.4|$ \\
\hline Total auditory & $135.9 \pm 31.5$ & $189.2 \pm 18.4$ & 0.001 & $-70.3,-36.33$ \\
\hline
\end{tabular}

Notes: Bold values are the total score of the test (as a whole). Al Maad is a symbol used in Arabic to indicate that the sound (for pronunciation) is longer; Al Shadd is a symbol used to indicate that a sound should be pronounced twice.

Abbreviation: SLD, specific learning disabilities. 
Table 6 Comparison between the mean scores of basic and post-training Arabic, mathematics, and writing tests of students with SLD $(\mathrm{n}=19)$

\begin{tabular}{|c|c|c|c|c|}
\hline \multirow[t]{2}{*}{ Items } & \multirow{2}{*}{$\frac{\text { Basic }}{\text { Mean } \pm \text { SD }}$} & Post-training & $P$-value & \multirow{2}{*}{$\begin{array}{l}95 \% \text { confidence } \\
\text { interval }\end{array}$} \\
\hline & & Mean \pm SD & & \\
\hline Total ART & $32.4 \pm 20.5$ & $76.2 \pm 18.1$ & 0.001 & $-56.46,-31.02$ \\
\hline Total mathematics test & $2.1 \pm 1.6$ & $12.7 \pm 3.8$ & 0.001 & $-12.54,-8.73$ \\
\hline Writing test & $66.2 \pm 14.4$ & $99.9 \pm 12.3$ & 0.001 & $-42.58,-24.95$ \\
\hline
\end{tabular}

Abbreviations: ART, Arabic reading test; SLD, specific learning disabilities.

This improvement in handwriting is due to the effect of training on visual motor integration, because it is the primary predictor of handwriting performance and learning academic skills. ${ }^{45}$ Mastering the basic geometric shapes is a prerequisite before the child learns to write. ${ }^{46}$ It has been noticed that as children's ability to copy the forms on VMI increases, a concomitant increase in ability to copy letters accurately is noticed. ${ }^{47}$

Subsequent studies ${ }^{48,49}$ referred to the importance of visuo-motor skill training, including multisensory (visual, auditory, and visuo-motor skills) training and computerassisted instructions, among the key factors that contributed to improving the achievement of students with dysgraphia.

Reading fluency is of critical importance because text reading that is disfluent is slow and may impair the child's ability to comprehend. In overcrowded classrooms, there is a lack of guided oral reading instructions and little concern with reading fluency. The poor reading instructions, in many of our overcrowded classrooms, play a role in defective reading comprehension. Moreover, the National Reading Panel ${ }^{50}$ reported that the effects of phonemic awareness instructions are intensified and improved when combined with reading instructions. The insignificant progress in reading comprehension after implementation of the newly constructed cognitive rehabilitation program, in the current study, might be an indication for the need of more extended sessions for the enhancement of reading comprehension. In contrast, this insignificant improvement is consistent with the previous study of Adams $\mathrm{s}^{51}$ who found that children in later primary grades who received cognitive instructions (by visual, auditory, and visuo-motor instructions) as a training program were better able to decode and spell words and to read text orally, but their comprehension of text did not significantly improve.

\section{Conclusion}

1. The newly constructed cognitive training computerized battery including multisensory training modalities (visual, auditory, and visuo-motor trainings) is of utmost importance for cognitive enhancement when tailored for each student according to his/her previously diagnosed cognitive skill deficits.
2. This enhancement in cognitive skills will be reflected in improvement in academic achievement level, and requires frequent follow up.

\section{Acknowledgments}

The authors thank Baha Soliman, a computer programmer specialist, Assiut University, for his kind support and advice. They also thank all staff members, colleagues, employees, and workers of the Department of Neuropsychiatry, Faculty of Medicine, Assiut University, for their great help and encouragement and all students who agreed to participate in our study, and school staff members who also facilitated our work.

\section{Author contributions}

All authors contributed toward data analysis and drafting and revising the paper and agree to be accountable for all aspects of the work.

\section{Disclosure}

The authors report no conflicts of interest in this work.

\section{References}

1. American Association of Intellectual and Developmental Disabilities (AAIDD). Definition of Intellectual Disability. 2010. Available from: http://www.aamr.org/content_100.cfm?navID=21. Accessed August 1, 2010.

2. Torgesen JK, Barker TA. Computers as aids in the prevention and remediation of reading disabilities. Learn Disabil Q. 1995;18: 76-87.

3. Thouvenelle S. Do computers belong in early childhood. Scholastic Early Childhood Today. 1994;8(5):48-50.

4. Male M. Technology for Inclusion. Meeting the Special Needs of all Students. 3rd ed. Boston: Allyn and Bacon; 1997.

5. Zorzi M, Barbiero C, Facoetti A, et al. Extra-large letter spacing improves reading in dyslexia. Proc Natl Acad Sci U S A. 2012;109(28): 11455-11459.

6. Perea M, Panadero V, Moret-Tatay C, Pablo Gómez P. The effects of inter-letter spacing in visual-word recognition: evidence with young normal readers and developmental dyslexics. Learn Instr. 2012;22: 420-430.

7. Green CS, Bavelier D. Learning, attentional control, and action video games. Curr Biol. 2012;22(6):R197-R206.

8. Franceschini S, Gori S, Ruffino M, Viola S, Molteni M, Facoetti A. Action video games make dyslexic children read better. Curr Biol. 2013;23(6):462-466 
9. Ehri LC, Nunes SR, Willows D, et al. Phonemic awareness instruction helps children learn to read: evidence from the National Reading Panel's meta-analysis. Read Res $Q$. 2001;36:250-283.

10. National Institute for Literacy. Developing Early Literacy: Report of the Early Literacy Panel: A Scientific Synthesis of Early Literacy Development and Implications for Intervention. Jessup, MD: National Institute for Literacy; 2008.

11. Collet G, Colin C, Serniclaes W, et al. Effect of phonological training in French children with SLI: perspectives on voicing identification, discrimination and categorical perception. Res Dev Disabil. 2012; 33(6):1805-1818.

12. Russo NM, Nicol TG, Zecker SG, Hayes EA, Kraus N. Auditory training improves neural timing in the human brainstem. Behav Brain Res. 2005;156(1):95-103.

13. Veuillet E, Magnan A, Ecalle J, Thai-Van H, Collet L. Auditory processing disorder in children with reading disabilities: effect of audiovisual training. Brain. 2007;130(pt 11):2915-2928.

14. Bogliotti C, Serniclaes W, Messaoud-Galusi S, Sprenger-Charolles L. Discrimination of speech sounds by dyslexic children: comparisons with chronological age and reading level controls. J Exp Child Psychol. 2008;101(2):137-175.

15. Achtman RL, Green CS, Bavelier D. Video games as a tool to train visual skills. Restor Neurol Neurosci. 2008;26(45):435-446.

16. Abou El-Ella MY, Sayed EM, Farghaly WM, Abdel-Haleem EK, Hussein ES. Construction of an Arabic reading test for assessment of dyslexic children. Neurosciences (Riyadh). 2004;9(3):199-206.

17. Farghaly MS. Uses of Ultra-Cognitive Strategies in Diagnosis and Treatment of Students with SLD; Mathematic Achievement Test for Fourth Grade Primary Students [theses]. Asyut City: Faculty of Education, Asyut University; 2001.

18. Melika L, Ismael M. Wechsler Intelligence Scale-Revised (3rd Arabic Version). Cairo, Egypt: Egyptian Anglo Library; 1999.

19. Wechsler D. Wechsler Intelligence Scale for Children. New York: Psychological Corporation; 1974.

20. EL-Behairy A, Aglan A. Test for Attention Deficit Disorder (School Form). Cairo, Egypt: Library of Egyptian Nahda; 1997.

21. Conners KC. The Conners 'Rating Scales-Revised (CRS-R). North Tonawanda, NY: Multi-Health Systems, Inc.; 1970.

22. Farghaly W, Ahmed M, Elmestikawy T, et al. Construction of an Arabic computerized cognitive skill battery for the diagnosis of children with specific learning disabilities. J Curr Med Res Pract. 2016;1:38-46.

23. International Dyslexia Association. What Is Dyslexia? 2002. Available from: http://www.interdys.org/FAQWhatIs.htm. Accessed May 31, 2017.

24. Warmington M, Stothard S, Snowling M. Assessing dyslexia in higher education: the York adult assessment battery-revised. J Res Spec Educ Needs. 2013;13(1):48-56.

25. Capellini SA, Padula NAMR, Santos LCA, Lourenceti MD, Carrenho EH, Ribeiro LA. Desem penhoemcon sciência fonológica, memória operacional, leiturae escritana dyslexia familial. Pro Fono. 2007;19: 374-380.

26. Ramus F, Rosen S, Dakin SC, et al. Theories of developmental dyslexia: insights from multiple case study of dyslexic adults. Brain. 2003;126(pt 4):841-865.

27. Stanovich KE, Siegel LS, Gottardo A. Converging evidence for phonological and surface subtypes of reading disability. J Educ Psychol. 1997;89:114-127.

28. Germano GD, Capellini SA. Efficacy of an audio-visual computerized remediation program in students with dyslexia (original title: Eficácia do programa de remediação auditivo-visual computadorizado em escolares com dislexia). Pró-Fono Revista de Atualização Científica. out-dez. 2008;20(4):237-242.

29. Hale J, Alfonso V, Berninger V, et al. Critical issues in response to intervention, comprehensive evaluation, and specific learning disabilities identification and intervention: an expert White Paper consensus. Learn Disabil Q. 2010;33:223-236.

30. Lie A. Effects of a training program for stimulating skills in word analysis in first grade children. Read Res Q. 1991;26:234-250.
31. Hecht SA, Close L. Emergent literacy skills and training time: scientific Studies of Reading; training in disadvantaged kindergartners. $J$ Exp Child Psychol. 2002;82(2):93-115.

32. Shaywitz S. Overcoming Dyslexia: A New and Complete Science-Based Program for Reading Problems at any Level. New York, NY: Vintage Books; 2003.

33. Magnan A, Ecalle J. Audio-visual training in children with reading disabilities. Comput Educ. 2006;46(4):407-425.

34. Temple E, Deutsch GK, Poldrack RA, et al. Neural deficits in children with dyslexia ameliorated by behavioral remediation: evidence from functional MRI. Proc Natl Acad Sci U S A. 2003;100(5):2860-2865.

35. Foorman BR, Arndt EJ, Crawford EC. Important constructs in literacy learning across disciplines. Top Lang Disord. 2011;31(1):73-83.

36. Lyytinen H, Aro M, Elklund K, et al. The development of children at familial risk for dyslexia: birth to early school age. Ann Dyslexia. 2004;54(2):184-220.

37. Lovett M, Barron R, Frijters J. Word identification difficulties in children and adolescents with reading disabilities: intervention research findings. In: Swanson HL, Harris K, Graham S, editors. Handbook of Learning Disabilities. New York, NY: Guilford Press; 2013:329-359.

38. Christensen C, Wauchope M. Whole school literacy: Using research to create programs that build universal high levels of literate competence. In: Rosenfield S, Berninger V, editors. Implementing Evidence-Based Interventions in School Settings. New York: Oxford University Press; 2009:501-526.

39. Liberman AM. How theories of speech affect research in reading and writing. In: Blachman BA, editor. Foundations of Reading Acquisition and Dyslexia. Mahwah, NJ: Lawrence Erlbaum Associates; 1997:3-19.

40. Pennington BF. Toward an integrated understanding of dyslexia: genetic, neurological, and cognitive mechanisms. Dev Psychopathol. 1999;11(3):629-654.

41. Byrne B, Liberman AM. Meaningless, productivity and reading: some observations about the relation between the alphabet and speech. In: Oackhill J, Beard R, editors. Reading Development and the Teaching of Reading: A Psychological Perspective. Oxford: Blackwell; 1990: 157-173.

42. Mahwah NJ, LEA, Perfetti CA. Comprehending written language: a blueprint of the reader. In: Brown $\mathrm{CM}$, Hagoort $\mathrm{P}$, editors. The Neurocognition of Language. Oxford: Oxford University Press; 1999: 167-199.

43. Oliver CE. A Sensorimotor program for improving writing readiness skills in elementary-age children. Am J Occup Ther. 1990;44(2): 111-116.

44. Gerogia AD. A comparison of structured sensorimotor therapy and child centered activity in the treatment of preschool children with sensorimotor problems. Am J Phys Med. 1999;53:110-114.

45. Sovik N. Developmental Cybernetics of Handwriting and Graphic Behaviour. Boston: Universitetsforlaget; 1975.

46. Beery KE. Revised Administration, Scoring and Teaching Manual for the Developmental Test of Visual-Motor Integration. Cleveland: Modern Curriculum Press; 1982.

47. Weil MJ, Amundson SJ. Relationship between visuomotor and handwriting skills of children in kindergarten. Am J Occup Ther. 1994;48: 982-988.

48. Wanzek J, Vaughn S, Wexler J, Swanson EA, Edmonds M, Kim AH. A synthesis of spelling and reading interventions and their effects on the spelling outcomes of students with LD. J Learn Disabil. 2006;39(6): 528-543.

49. Feder K, Majnemer A. Handwriting development, competency, and intervention. Dev Med Child Neurol. 2007;49(4):312-317.

50. National Reading Panel. Teaching Children to Read: An EvidenceBased Assessment of the Scientific Research Literature on Reading and its Implications for Reading Instruction. Washington, DC: National Institute of Child Health and Human Development; 2000.

51. Adams MJ. Beginning to Read: Thinking and Learning About Print. 1st ed. Cambridge, MA: The MIT Press; 1990. 
Neuropsychiatric Disease and Treatment

Dovepress

\section{Publish your work in this journal}

Neuropsychiatric Disease and Treatment is an international, peerreviewed journal of clinical therapeutics and pharmacology focusing on concise rapid reporting of clinical or pre-clinical studies on a range of neuropsychiatric and neurological disorders. This journal is indexed on PubMed Central, the 'PsycINFO' database and CAS,

and is the official journal of The International Neuropsychiatric Association (INA). The manuscript management system is completely online and includes a very quick and fair peer-review system, which is all easy to use. Visit http://www.dovepress.com/testimonials.php to read real quotes from published authors.

Submit your manuscript here: http://www.dovepress.com/neuropsychiatric-disease-and-treatment-journal 